\title{
Doing Research, Doing Politics: ICT Research as a Form of Activism
}

\author{
Juliet Webster
}

equality.research@debeauvoir.co.uk

\begin{abstract}
Why do we do research into ICTs and society at all? Apart from advancing our analytical understanding of technological and social change, for many researchers, social studies of technology provide a way of supplying evidence for social policy, or shaping social practice. Even if we do not always make it explicit, for many of us, our research is both political and personal.

In this paper, I consider the ways in which social and political values shape research questions and research methods. Drawing on examples of recent feminist and other research which has investigated the employment relations of technological change, I discuss the academic and political ambitions of the work, the recognition of interests and the involvement of stakeholders, and the relationship between researchers and 'users' of the research. I reflect on the importance of revealing and explicating the politics of ICT research, particularly in the context of imminent economic and social restructuring.
\end{abstract}

Keywords: ICTs, politics, research, engaged research, values

Acknowledgement: This paper was presented as keynote speech at the ICTs and Society conference, which took place in Castelldefels, Spain from 30 June to 2 July 2010. The Unified Theory of Information Research Group organised this international event with superb efficiency. Wolfgang Hofkirchner solicited and supported the preparation and presentation of this paper. I received extremely helpful comments for improving it from two reviewers. Many thanks to you all.

\section{Why Conduct Research Into ICTs and Society?}

I was eighteen years old. My urge for freedom was bumping against the walls that the dictator had erected around life. My life and everybody else's life. I wrote an article in the Law School's journal, and the journal was shut down. I acted in Camus' Caligula, and our theater group was indicted for promoting homosexuality. When I turned on the BBC world news to hear a different tune, I could not hear a thing through the stridency of radio interference. When I wanted to read Freud, I had to go to the only library in Barcelona with access to his work and fill out a form explaining why. As for Marx or Sartre or Bakunin, forget it - unless I would travel by bus to Toulouse and conceal the books at the border crossing, risking the unknown if caught transporting subversive propaganda. And so, I decided to take on this suffocating, idiotic, Franquist regime [...] (Castells, 2009, p. 1)

These are the opening lines of Manuel Castells' book, Communication Power. In this introduction, he sets out the reasons why he cares about the control of information and communication, how this control confers political power, and why it is therefore so important to struggle for free communication. Castells grew up under the Franco regime in Spain, a stiflingly repressive environment, and his experiences profoundly shaped his approach to research and the issues that his research has tackled over the years. As he writes in the book's acknowledgements:

\section{[...] this is [...] a special [book] for it brings together my research and my desire for a}

world made better by people communicating freely (Castells, 2009, p. xii, my emphasis).

The environment that Castells grew up in, and in which he cut his political and social teeth, was particularly brutal and authoritarian. Though this type of regime was by no means unique to Spain in the $20^{\text {th }}$ century, many of us are fortunate not to have spent our formative years constrained by 
such political systems. However, we are all to some extent shaped by our social environments and by our responses to them, and no matter what the nature of these environments and our reactions are, they shape our approach to our work and the research priorities we set ourselves. Even if we don't consciously acknowledge it to ourselves or to make it an explicit objective of our research, many of us do social research into ICTs for much the same reasons - our desire to somehow contribute to a better world.

Although personalising one's academic research agenda in such a way is not always approved of (and in fact it is usually actively discouraged), I believe that there is a need to make explicit our political reasons for doing social research into ICTs, and our aspirations about the outcomes of the research. I argue for this on the grounds of clarity, intellectual honesty, and academic rigour: only when we excavate and reveal our well-meaning motivations and reasoning, can we develop meaningful research questions and the conceptual framework which are the necessary preconditions to any effective research project.

In this paper, I start by discussing how critical social research into ICTs, guided by the desire to promote a better world, has sometimes been subverted by dominant social interests which have different objectives, based more wealth creation and economic growth rather than social improvement. In this process, technological innovation has been presented as neutral, and the social values inherent in analysing technological change for these dominant social groups have been rendered invisible. I advocate instead research which has been framed and conducted according to explicated, transparent and progressive social values, as a consequence of which it is both intellectually rigorous and politically inspirational. This 'engaged research' can be done in several ways: by framing the research to explicitly contribute to a better world for us all, by developing and using innovative methodologies, by involving and including stakeholders in the research process, by pursuing particular social values in the conduct of the research, or by reaching out to particular users with the research findings. The paper considers examples of each of these ways of conducting engaged research into technological innovation and implementation. My argument is that ICT research can be engaged in just these ways; in fact, it cannot really be divorced from the social project of striving for a better world, and nor should it. Indeed, for me personally, and for many other ICT researchers, an explicit objective of doing ICT research (indeed any research) is to support and contribute to progressive social change in some way.

\section{ICT Research is Not Always Engaged with Social Values}

Despite the fact that many of us want to conduct 'engaged research' into ICTs, this research is often guided by pragmatism rather than by social critique. In many countries, there is and has been for some twenty or more years, a discernible body of work which is concerned primarily with interpreting technological innovations as socially neutral processes or with the practicalities of ICT implementation. There are strong pressures on researchers, particularly in a context of economic crisis and restructuring, to retreat into this type of work. In this context, critical social research often becomes displaced by research which is driven by an over-optimistic technological agenda. Researchers find they have to survive in a world where economic growth and constant innovation are the leitmotifs underlying not only economic but social policy. For instance, in the 1980s, a trend emerged in UK ICT studies for the adoption of 'an overly positivistic and optimistic version of consultancy strategy-speak' (Rod Coombs 1992, personal communication). Because of the dominant political culture in which we were then living, there was a pervasive pressure to adopt a discourse of the private sector and business enterprise in our research priority setting, question posing and project conduct. This reflected the political, cultural and financial climate we found ourselves working within, which shaped the research issues that were valued through public funding support. In the intervening years, the policy pressure for constant economic growth has not diminished, nor has it been restricted to the UK: since the early 1990s it has been a central policy ambition across the EU, and in many of its other Member States to promote constant economic growth through constant technological innovation (see, for example, Commission of the European Communities 1993; European Commission 2010). 
The partiality of a research agenda dominated by these priorities is usually concealed: the politics of this type of ICT research are not often discussed or criticised, but rather, presented as socially neutral. In Thatcherite Britain, the research priorities of the business community dominated other research priorities, but in the context of cost-cutting and the dominance of competitiveness priorities in the 1980s, it became an exhortation to address these particular policy objectives rather than those which might benefit other or all sections of the community. As a result, ICT researchers were forced through funding priorities into engaging with a very particular type of policy and politics - primarily the policy agenda of private industry and the business community.

At the same time, and consequently, the dominance of this policy agenda led to a re-orientation of research priorities away from the multi-faceted social and economic implications of information and communication technologies. In the technology studies research community, there was a preoccupation with the obstacles to successful innovation and implementation of new technologies, the 'business case' for particular technological arrangements, the redesign of business processes with the aid of ICTs, the strategies which are necessary for the exploitation of new technologies, and with change management.

Yet there were profound social problems in the advanced economies at the time, not least the unprecedented levels of unemployment which resulted from wholesale industrial restructuring, nascent globalisation and some technological job displacement. These issues, and their consequences were not priority areas for ICT research. As a result, there were enormous pressures on researchers to suspend critical social thinking in relation to ICTs and to abandon any focus on the social issues, and perhaps problems, surrounding technological change. Because the widespread benefits of technological change were largely taken for granted, research which unpacked and examined the social relations involved in the creation and implementation of new technologies became a somewhat subversive and minority activity. Yet such critical examination is the first vital precondition for engaged social research into ICTs.

There are strong pressures, then, particularly in a context of economic crisis and restructuring, to concentrate on research that supports dominant economic interests. The pressure to ignore the social in favour of the economic can be very difficult to resist when there are political conditions attached to funding provision, and in the context of financial stringency in the research world. In the current climate of fiscal and social retrenchment, we need a sharp awareness of the likely pressures on us to again concentrate our research efforts on positivistic economy-building ICT research.

In the next part of this paper, I want to consider some aspects of engaged ICT research, with reference to studies which have scrutinised the social relations involved in ICT creation and implementation, have participated in the development of 'alternative technologies', have proposed alternative methodologies of ICT development, have actively involved wide groups of stakeholders in the research process, and so aims itself to change social practice and the social arrangements surrounding ICT systems.

\section{Rethinking the Relationship Between ICTs and Society has Facilitated Intervention in Both}

When ICTs first emerged in the early 1980s, there was a tendency in much social debate to treat ICTs (or microelectronics, as we knew them then) as neutral artefacts which were independent of the social relations in which they emerged and were developed. These technologies had effects. In different academic accounts, these effects or presumed effects were either positive or negative. They might lead to mass unemployment, or greater leisure for all. They might bring about closer social connections, or create an atomised society in which people were increasingly separated and alienated from one another. We might struggle to mitigate the effects of ICTs, or to promote the conditions in which their positive potential could be utilised - by enhancing employees' skills, by securing employers' agreements to minimise job losses, in some way attempting to alter the environment into which ICTs are introduced and in which they are used. But across the political and philosophical spectrum, it was common to focus on the effects of ICTs, less common to consider 
critically the artefacts themselves or the forces which shaped them. They were black boxes which had effects, but which we couldn't open to change.

A pre-condition for conducting engaged social research into ICTs is surely to open these black boxes. There are clear economic, political, and social forces involved in the development of technologies, including ICTs. For example, Langdon Winner has shown how the height of the bridges over the highways on Long Island were designed from the 1920s to achieve a particular social effect: that of allowing through the automobile-owning white upper and middle class while excluding the public transport-using poorer and black groups (Winner, 1985). David Noble has shown how, in machine-tool development, Computer Numerical Control was the technological solution favoured by managers and developers because it removed control over the tool from shop-floor engineers and placed it in the hands of white-collar office technicians, thus breaking the control over the labour process exercised by the skilled labour force (Noble, 1984).

Donald MacKenzie and Judy Wajcman collected these and other case studies in their defining work, The Social Shaping of Technology (1985), which prompted a re-evaluation of the neutrality of technology and began to reveal the socio-economic forces behind their development and implementation. The social construction of technology (SCOT) approach pioneered by Trevor Pinch and Wiebe Bijker (Bijker et al, 1987) and actor-network theory (ANT) articulated by scholars such as Bruno Latour (1987), developed this analysis of intersecting social and technical relations. The SCOT approach lays considerable emphasis on the involvement of clearly discernible social groups (those who appear in the historical record). Unfortunately, it overlooks the exclusion of particular groups by, for example, gender or ethnicity, which means that it is unable to account for the influence of structural social exclusion on technological development (Mackenzie and Wajcman, 1999). Nevertheless, in placing the role of social groups, including users, within the technological narrative, this approach reveals the human and social agency involved in the process of technological development. Many technological systems or artefacts have been analysed using one of these perspectives, from the QWERTY keyboard to the hotel door key to the bicycle to the refrigerator to the barcode. Even the city of Barcelona has been analysed in terms of the competing professional and political priorities which created 'technological frames' for the design and building of the Eixample, the Barcelona extension (Aibars and Bijker, 1997).

The social shaping of technology (SST), SCOT and ANT perspectives all provide a muchneeded corrective to the idea that technologies are immutable and have effects, and users are the passive recipients of their intrinsic qualities. Instead, these approaches show the complex interrelationships between technological and social forces, and the many influences upon them. The SST is the theoretical approach that has most shaped my own perspective on ICT research, because in considering exactly how and why technologies are developed and constituted, it privileges the social relations, political programmes and economic objectives involved in technological development. Once we recognise these, we start to see the potential, at least, for using social research into technology not only as a way of interpreting the world, but also as a way of changing it. The fact that social relations and technologies intersect and are mutually constitutive, means that through our developing understanding of ICTs, we can struggle to advance our own, progressive, social objectives. This, at least, is my personal reason for engaging in technology studies, and many of us perhaps work with this aspiration constantly in the back of our minds.

Despite these intellectual advances which have laid bare the fallacy of the idea that technology is neutral, I still sometimes miss a sense of the social values, if any, underlying this research: the idea that there are certain sets of progressive socio-technical arrangements that we might advocate or struggle for, because they are more likely to respond to certain political objectives - improved social inclusion, better gender equality, more satisfying work, less poverty, for instance. Technology and society studies certainly provide a more robust theoretical framework for the analysis of technological changes, including ICTs. But are all technologies and all social arrangements equal in the eyes of the research community? Although over the past twenty years there seems to have been little success in moving popular discourses of technological change away from technological determinism and enchantment, I am making a plea for us to keep pushing, where we 
can, to undertake research which is both theoretically inspired and politically engaged. We all recognise that we live in a society marked by profound social and economic problems; as researchers, we can deploy our insights to some socially useful purposes.

\subsection{Researchers Can Contribute to Shaping New Technologies for 'Progressive' Social Objec- tives}

What does politically engaged ICT research look like? In order to address this question, I want to review some examples of practical research into technology which has been undertaken in the past with the explicit political objective of using the moment of technological change to simultaneously pursue social change. These examples serve to show what contribution ICT researchers can make to the development of 'alternative' technological arrangements to address the social, economic and environmental challenges facing advanced societies.

In the 1980s, sections of the labour movement throughout Europe developed a critique of technological innovation solely in the interests of business. They deplored the development and implementation of manufacturing technologies which either deskilled workers or displaced them completely from employment. They noted that advanced capitalism, through the combined interests of the military-industrial complex, energetically develops technological systems for purposes which add little to the welfare of citizens, while at the same time the social problems of poverty, ill-health, disability and social exclusion persist.

The following example from the UK illustrates this approach to engaged research into technology, although similar projects were undertaken elsewhere, notably in Germany and in the Nordic countries (Rauner et al, 1988; Ehn, 1989). Faced with the closure of a large British armaments factory due to declining orders in the mid 1980s, a time of high unemployment, the company's employees looked for ways to prevent the plant, the skills and the workforce simply being thrown on the scrapheap. In a project known as the Lucas Plan (because it was undertaken in Lucas Aerospace), a co-operative of trade unionists, researchers and practising engineers developed proposals to reconfigure the existing plant, and to use the same raw materials and workforce skills to make a series of socially useful technologies, including a lightweight road-rail bus, an artificial kidney, and a cheap-to-run gas-fuelled heating pump for use in large-scale housing projects - transforming swords into ploughshares (Wainwright and Elliot, 1982). Although some of the technological proposals responded to the social problems of the UK in the 1980s, they have not lost their relevance for today.

This project spawned an alternative politics of intervention in the design and introduction of new technologies in the workplace, designed explicitly to protect the working conditions of employees, promote the development of technologies with a social purpose, and to campaign for the development of the 'socially useful economy'. The idea of promoting human centred systems which are part and parcel of a 'socially useful economy' has lost none of its salience, given our widely-shared, current economic crisis. In their book Developing the Socially Useful Economy, Bodington, George and Michaelson (1986) set out guidelines for human-centred systems design which departed from the then prevalent pattern of systems design for job displacement. Human-centred systems design involved:

- Each human user controlling the part of the system with which they interacted

- Systems flexible enough to allow human users to develop their skills (not a given, see bank workers, shop workers using proceduralised systems)

- No monitoring or pacing of work by systems (compare with computer-telephony integration in call centres)

- The design of jobs as an integral part of the systems design which had to cater for other human needs, such as job satisfaction, health and safety. 
Here, then, researchers not only recognised the dominant social relations involved in the shaping of technological systems, but advocated alternative interests and guiding principles to be embedded in these systems, and developed a method for placing the interests of employees at the centre of the design process. Methodological innovation, I want to argue, is a key element of engaged research, and I consider this element in the next section of this paper.

\subsection{Engaged Research Leads to Methodological Innovation}

The technological product of the Lucas Plan was obviously important for advancing social inclusion. It was also revolutionary because of the systems development methods it used, and the ways in which it involved wider groups of interests than those represented solely by business in the development of these technologies. Users' needs were treated as the main design criterion, and the process of technological development privileged the experiences and priorities of workers at every step.

One difficulty with this project and others like it, however, was that the 'human' in 'humancentred systems' was in fact male: there was little attention to the gender power relations of technology. This deficit was tackled by the 'Sheffield Office Systems Project', conceived and executed in the late 1980s (Green, Owen and Pain, 1993). The purpose of this work was to develop a new library system for the city of Sheffield; it drew on the 'human-centred systems' approach, which, as we have seen, rejected technological developments centred solely on the needs of multinationals or on the formal methods central to the work of ICT professionals, and placed human values, human needs and participative processes at the centre of systems design.

It also introduced a gender perspective into ICT design. The project was, after all, concerned with the development of library systems: the vast majority of the workers concerned were female, their jobs were to be profoundly affected by these innovations, and traditionally, female office workers have always been firmly excluded from technological decisions or development processes. That the labour force has two sexes, vertically and horizontally segregated and with very different experiences of technological change processes, is not always recognised, including by those involved in alternative technology projects. This project was concerned to

The Sheffield project, like its predecessors in Lucas and elsewhere, used participative methods which are fundamentally empowering to users. There were two main elements: the formation of a long-term, broad-based inter-disciplinary design team, and the use of the 'study circle' method to promote iterative solutions and develop prototypes. Study circles emphasised the social requirements and social context within which systems are to be used, and provide for social and organisational relations to be embedded in the design process. Their work was participative, long-term and valued the perspectives of all the participants. This was in sharp contrast to conventional ICT development teams which feminist researchers such as Woodfield (2002) have since shown to favour technical input over social or hybrid skills. Both inter-disciplinary design teams and study circles took control over the innovation out of the hands of commercial players or ICT professionals, and placed it with user-managers. Moreover, participation by users meant that the systems were not designed in the abstract, but their design was firmly located in the organisational context, the bodies of knowledge and skill, and the culture and values of the public sector.

The active, direct and close involvement of users in the process of developing a new technological system, such as that developed in the Sheffield project, is rare in ICT research, but it is an extremely important aspect of engaged ICT research. It gives the subject of the research a voice in the analysis of the technology and influence over the development of new systems and methods with long-term ramifications for their working lives. In ICT development projects, women are particularly absent and even where present, invisible. They are badly represented among ICT professionals (Cohoon and Aspray, 2006; BCS, eSkills UK and Intellect, 2008) and, as ICT users, tend to be clustered in low status jobs with little influence over change processes (Green, Owen and Pain 1993; Webster 2010). As a result of their invisibility and poor status, their viewpoints are poorly represented and their perspectives on work are invariably under-valued (Woodfield 2002; Glover and Guerrier 2010). 


\subsection{Engaged ICT Research Involves 'Stakeholders' in the Research Process}

The Sheffield team developed 'study circles' which included the end users (librarians) of the office system under development, as well as engineers and library managers. The project showed the potential for, and the importance of, direct user involvement in engaged ICT research projects. But there are other stakeholders in technology development and research projects whose perspectives are equally important. These stakeholders can be included in the setting of research agendas and the conduct of research, as well as in the dissemination of end results.

A recent study of service workers' engagement with ICTs did draw female retail and banking workers into the research process (Webster 2010). The study examined the issue of whether all social groups were active participants in the transition to the so-called 'knowledge society', and if not, whether this was a problem for an economically and socially sustainable Europe. Empirically, the project was concerned with understanding whether the introduction of networked ICT systems afforded women in junior service jobs (those working as cashiers or call centre workers in banks, and as customer assistants in highly automated retail outlets) new opportunities to develop their skills, knowledge, and careers, and so to progress from 'poor jobs' into better jobs.

There were several stakeholder groups which were directly interested in both the design and the outcome of the work. Policy makers at regional, national and international levels were interested in the project's implications for vocational training systems, and for working time policies. Employment and skills public bodies wanted to draw out the lessons for work organisation and for improving the skills of low-skilled women. Trade unions were keen to get an assessment of the patterns of women's access to new skills and training provision, and in what these revealed about the quality of their working lives.

Representatives of all these groups were therefore placed at the centre of the design of the research questions and project methodology. They contributed their perceptions of the pressing issues concerning women's work to the research design: they identified problems with working hours, unequal access to training, and bottlenecks in their organisations which limited women's progression. Trade unions and their representatives were particularly important in identifying the key issues in workplaces, in getting access to the workplaces for case studies and interviews, and in disseminating the project results through their structures (Webster 1999; Webster, 2002). All shared the same broad set of objectives, which were to address the stark concentration of women at the bottom of these organisations, and to examine how their skills might be better developed and used.

In my view, the inclusion of stakeholders like trade union and employees' representatives, as well as employers, in ICT research is as important as the involvement of direct end users. These are the groups and individuals who are close to innovation processes, and are able to identify potential issues, needs and requirements, see patterns of under-representation that need addressing and voices that may not be heard, identify implications of particular developments and put in place practical actions addressing these. They may not be directly affected by processes of technological change, but they are usually directly involved in influencing and shaping them, and in building cooperation with different actors to create changes. So their perspectives are crucial and their ability to connect with direct users is invaluable.

Researchers in many fields do not always recognise and include these groups in the research process, yet their inclusion is vital to the social relevance and application of the research we do. This is particularly so for research concerned with the social relations and implications of ICTs. Stakeholders' closeness to the field of the research and their immersion in the social landscape provides them with an invaluable perspective which competent social researchers are well advised to consider. Their priorities, too, can help to guide researchers' thinking about framing the research and addressing key issues. This makes stakeholders more than simply research informants, but more like agents in the research process.

Involving stakeholders in this way is not uncomplicated, however, for their perspectives are necessarily particular to their situation and interests, which are not necessarily those of the researcher. In drawing them into the research process and listening to their voices in the formulation 
of research questions, therefore, we also have to maintain a clear sense of the role their contribution plays in the shaping of our own analysis; this is likely to be guided by a theoretical and conceptual framing which is influenced by other research and by our intellectual, practical and, I would argue, political priorities as well as by our stakeholders' particular concerns. This underlines the importance of clarity in our own motivations for doing social research into ICTs.

\subsection{Engaged ICT Research Aims to Change Practices and Policies}

The projects discussed above are exemplary of the 'engaged ICT research' I am proposing here: they are strongly theoretically grounded, empirically geared to achieving social change and methodologically innovative. They are able to make a strong academic contribution, but never by setting the work apart from the practical problems, the solution to which our field can make such a difference. For what is the point of doing research that is theoretically elegant but has nothing to say about the world it theorises, or even of doing research that is empirically well designed but does not seek to use the results of that work to engage with those who might make use of it?

So I am arguing for more research that not only advances theoretical frameworks and methodological approaches, but also uses these advances as a means to address social problems through an engagement with policies and practices - not as an end in themselves. In other words, I am advocating doing, and celebrating doing, research that speaks not only to other researchers but also directly to social groups who need evidence to struggle for improvements to their world. ICT research could not be more practical and more connected to the social world. There is no reason why this research and the world it investigates should be anything but intimately inter-connected.

ICT research is no more neutral than ICTs themselves. It embeds our social values, relationships, our objectives and our aspirations. Research is also a personal labour process - we create something from it and put something of ourselves into it. In many cases, including my own, feminist and socialist politics are at the core of the work we do, and we do ICT research with the ambition of contributing to the improvement of the conditions of working and living of us all. As well as acknowledging the engagement of the personal in guiding the values and conduct of the research process, we should encourage, celebrate and promote engaged ICT research.

\section{Concluding Comments: Conducting ICT Research to Make a Difference}

ICT research is sometimes conducted without much reference to the social, economic and political context within which ICTs are created and implemented, as if both the technological arrangements and the research assessing them are neutral processes. Research of this kind, which does not start from an explicit objective to address social problems or improve social conditions, can be easily co-opted to the objectives of the socially and economically dominant, which are likely to be much more partisan. There are historical instances of ICT research becoming profoundly positivist and optimistic as alternative research agendas for wider social objectives become more difficult to pursue. In these circumstances, it becomes all the more important to be clear about our values, beliefs and personal reasons for engaging in knowledge generation and exchange, whether about ICTs, or indeed about all socio-economic developments. For many, if not for most of us, this is to contribute to a better world.

In my view, it is hard to justify any research that does not at least have some social application, and that declares its relevance and its social ambitions. ICT research is particularly exemplary of this need for relevance, for it is so obviously concerned with social changes which have real, everyday implications for people's work and lives. As a tool for shaping social change, engaged ICT research can play a vital role in provide evidence of, and strategies for addressing social problems.

In this paper I have highlighted some types of engaged ICT research. This is research which has a identifiable social project, which in turn is clarified in a number of ways: through the framing of the research to meet political objectives, through questioning the social objectives in the design of technologies, through the development and use of innovative methodologies, through the pursuit of 
particular social values in the conduct of the research, through the involvement and inclusion of stakeholders in the research process, or through engagement with particular users with the research findings. Defining engaged ICT research in relation to one or more of these characteristics, the paper has discussed examples of such research. Although I have drawn most of my examples from UK research and practical projects, I also want to acknowledge the intellectual and political legacy of research done elsewhere: particularly, for instance, the 'human-centred' research done in Germany and in the Nordic countries.

'Engaged research', then, is research which has the explicit objective of making a practical, as well as an intellectual, difference. Accepting that practical social objectives need to be an explicit aspect of ICT research may mean reconsidering our personal orientations to research, our understanding of the role of the researcher, and our relationships to our peers. As the discussion in this paper suggests, engaged research also involves intellectual innovations in the conduct of the research. For researchers in academia, engaged research also almost certainly means establishing much more direct and stronger relationships with those outside the academy who have a clear stake in the research issue - with employees, trade unions, NGOs, social institutions, public authorities and others. It is likely to involve a rethinking of the roles and relationships between different actors in research, and an acknowledgement of the different bodies of expertise they offer and their ability to make a contribution to the framing of research questions and the collection of data. And finally, it is likely to require an approach to communicating research results which has less to do with dissemination and more to do with dialogue and joint knowledge development. In the process, not only will the ambitions of the research be more closely engaged with the social problems that are apparent in a research domain, but the whole process of conducting research will be a little more democratised.

\section{References}

Aibar, E. \& Bijke. W. (1997). Constructing a City: Plan for the Extension of Barcelona. Science, Technology and Human Values, 22(1), 3-30.

BCS, eSkills UK \& Intellect (2008). Women in IT Scorecard. London: eSkills UK.

Bijker, W. E., Hughes, T. P. \& Pinch, T. (Eds.). (1987). The Social Construction of Technological Systems. Cambridge, MA: MIT Press.

Castells, M. (2009). Communication Power. Oxford: University Press.

Cohoon, J. M. \& Asprey, W. (Eds.). (2006). Women and Information Technology: Research on Underrepresentation. London: MIT Press.

Commission of the European Communities (1993). Growth, Competitiveness, Employment: The Challenges and Ways Forward into the 21st Century. Luxembourg: Office for Official Publications of the European Communities.

Ehn, P. (1989). Work Oriented Design of Computer Artifacts. New Jersey: Hillsdale.

European Commission (2010). Europe 2020: A strategy for smart, sustainable and inclusive growth. Brussels: European Commission, COM (2010) 2020.

Glover, J. \& Guerrier, Y. (2010). Women in Hybrid Roles in IT Employment: A Return to 'Nimble Fingers'? Journal of Technology Management and Innovation, 5(1), 85-94.

Green, E., Owen, J. and Pain, D. (1993). Gender, Information Technology and the Design of Office Systems. London: Routledge.

Latour, B. (1987). Science in Action. Milton Keynes: Open University Press.

MacKenzie, D. \& Wajcman, J. (1985). The Social Shaping of Technology. Milton Keynes: Open University Press.

MacKenzie, D. \& Wajcman, J. (1999). The Social Shaping of Technology. 2nd edition. Milton Keynes: Open University Press.

Michaelson, J., George, M. \& Bodington, S. (1986). Developing the Socially Useful Economy. London: Macmillan.

Noble, D. (1984). Forces of Production: A Social History of Industrial Automation. New York: Knopf.

Rauner, F., Rasmussen, L. \& Martin Corbett, J. (1988). The social shaping of technology and work: Human centred CIM systems. Al and Society, 2(1), 47-61.

Wainwright, H. \& Elliot, D. (1982). The Lucas Plan: a New Trade Unionism in the Making. London: Allison and Busby.

Webster, J. (1999). Technological Work and Women's Prospects in the Knowledge Economy: An Agenda for Research. Information, Communication and Society, 2(2), 201-221. 
Webster, J. (2002). Innovations in Information Society Sectors: Implications for Women's Work, Expertise and Opportunities in European Workplaces. Final Report of Project SERVEMPLOI, unpublished.

Webster, J. (2010). Clerks, Cashiers, Customer Carers: Women's Work in European Services. In D. Howcroft \& H. Richardson (Eds.), Work and Life in the Global Economy: A Gendered Analysis of Service Work. London: Palgrave.

Winner, L. (1985). Do Artifacts have Politics? In D. MacKenzie \& J. Wajcman (Eds.), The Social Shaping of Technology (pp. 26-38). Milton Keynes: Open University Press.

Woodfield, R. (2002). Woman and Information Systems Development: Not Just a Pretty (Inter)Face? Information Technology and People 15(2), 119-38.

\section{About the Author}

Juliet Webster

Juliet Webster is Visiting Professor on the Gender and ICT Programme at the Internet Interdisciplinary Institute (IN3), Open University of Catalunya. She is also the Director of Work \& Equality Research in London. She specialises in research and policy development on the working lives of women across the European Union, particularly the actions and policies necessary to improve their working conditions and prospects for advancement. She has held positions at the universities of Edinburgh, East London, Vienna, and Trinity College, Dublin, in DG Employment of the European Commission, and at the Involvement and Participation Association (IPA) in London. Her research currently focuses mainly on women in IT professions, and, at the other end of the labour market, on those in routine service jobs. Her books include Office Automation: the Labour Process and Women's Work in Britain, Shaping Women's Work: Gender, Employment and Information Technology and The Information Society in Europe: Work and Life in an Age of Globalisation. 